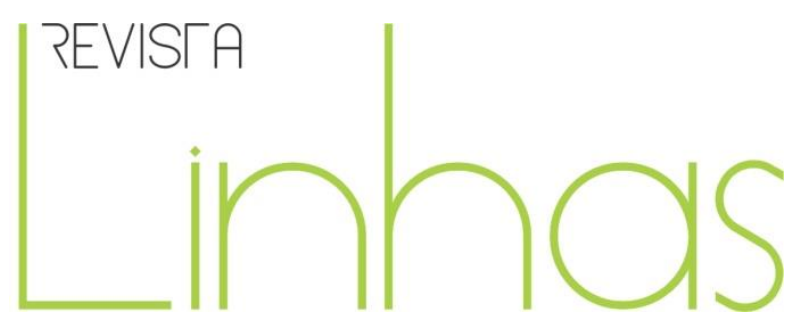

\title{
Políticas curriculares, diferença, pertencimento: ponderações sobre o uso do conceito de comunidades epistêmicas em chave pós-estrutural
}

\begin{abstract}
Resumo
Aborda-se o conceito de comunidade epistêmica tal como desenvolvido por Peter Haas, ponderando sobre possíveis (in)compatibilidades teóricas e heurísticas a partir da incorporação desse construto em pesquisas sobre políticas curriculares de corte pós-estrutural. A partir da investigação da subjetividade, da agência e da política nas teorias de Butler, Laclau e Mouffe, argumenta-se que, enquanto em um enfoque discursivo a própria atividade política produz a identificação comunitária em sentido performático, é concebível pensar que o conceito de comunidades epistêmicas segue a lógica estrutural da subjetividade política e do pertencimento, sugerindo que uma identidade grupal sólida anterior é condição para a ação social. Defende-se que a chave pós-estrutural apresenta maior produtividade e complexidade na abertura dos fenômenos políticos curriculares, embora possa ser produtivo manter aspectos característicos da abordagem das comunidades epistêmicas como forma de resguardar certa distinção sociológica das/nas linguagens de diferenciação cultural dos grupos atuantes/influentes na produção das políticas.
\end{abstract}

Palavras-chave: Comunidade Epistêmica. Diferença. Políticas Curriculares. Pós-Estruturalismo.

\author{
Clívio Pimentel Júnior \\ Universidade Federal do Oeste \\ da Bahia - UFOB - Barreiras/BA - \\ Brasil \\ clivio.pimentel@gmail.com
}

\footnotetext{
Para citar este artigo:

PIMENTEL JúNIOR, Clívio. Políticas curriculares, diferença, pertencimento: ponderações sobre o uso do conceito de comunidades epistêmicas em chave pós-estrutural. Revista Linhas. Florianópolis, v. 19, n. 41, p. 213-241, set./dez. 2018.
} 


\title{
Curricular policies, difference, belonging: ponderations on the use of epistemic communities concept in post-structural key
}

\begin{abstract}
We discuss the concept of epistemic community as developed by Peter Haas, pondering on possible theoretical and heuristic (in)compatibilities from the incorporation of this construct into curricular policies post-structural research. Departing from the investigation of subjectivity, agency, and politics in Butler, Laclau, and Mouffe's theories, it is argued that while in a discursive approach political activity itself produces community identification in a performatic way, it is conceivable to think that the concept of Epistemic communities follows the structural logic of political subjectivity and belonging, suggesting that a previous solid group identity is a condition for social action. It is argued that the post-structural key presents greater productivity and complexity in the opening of curricular political phenomena, although it may be productive to maintain characteristic aspects of the approach of the epistemic communities as a way to safeguard a certain sociological distinction in the languages of cultural differentiation of the working groups in the production of policies.
\end{abstract}

Keywords: Epistemic Community. Difference. Curricular Policies. Post-Structuralism. 
Chega mais perto e contempla as palavras.

Cada uma

tem mil faces secretas sob a face neutra e te pergunta, sem interesse pela resposta, pobre ou terrível, que lhe deres:

Trouxeste a chave?

Carlos Drummond de Andrade ${ }^{1}$

Em estudos mais recentes, inspirado em teorias pós-estruturais e pósfundacionais, tenho tentado compreender as dinâmicas políticas envolvidas na nomeação dos processos escolares das Ciências ${ }^{2}$ como Natureza da Ciência (Nature of Science). Nesse percurso, tenho me apoiado nas teorias de Ball (1994; 1998), Ball, Maguire e Braun (2016), Laclau e Mouffe (2015), Bhabha (2013), e no modo como Lopes (2012; 2015; 2016) Macedo $(2006$; 2015; 2016) e Dias $(2006$; 2016) têm incorporado tais registros às investigações em políticas curriculares. Nessa chave interpretativa, é possível abrir tais processos de nomeação como atos de poder constituídos discursivamente a partir de articulações de demandas em torno do significante Natureza da Ciência. Tais atos políticoidentitários são constitutivamente marcados por dinâmicas de disputas e interações complexas entre sujeitos e grupos epistêmicos, organismos nacionais e internacionais, lideranças governamentais e sindicais, entre outros agentes, em múltiplas arenas e escalas de circulação e significação, de modo que os discursos produzidos são sempre híbridos e bricolados, constituídos por fragmentos de sentidos de variados espaçostempos de pertencimento cultural (BALL, 2006; DIAS; LÓPEZ, 2006; LOPES, 2016; DIAS, 2016). Trata-se de uma abordagem complexa e encarnada da política, na qual se evitam análises do tipo de-cima-para-baixo ou de-baixo-para-cima, comumente restritas a tratamentos herméticos e contextualmente totalitários, cujas conclusões expressam-se

\footnotetext{
${ }^{1}$ ANDRADE, Carlos Drummond de. "Procura da Poesia". In: A Rosa do Povo. $31^{\text {a }}$ ed. Rio de Janeiro: Record, 2006.

${ }^{2}$ Refiro-me especificamente aos processos escolares de Ciências Naturais, Biologia, Química e Física, uma vez que os trabalhos acadêmicos cuja significação nodal faz referência à Natureza da Ciência apresentam discussões voltadas a esses componentes curriculares.
} 
com forte caráter determinista, sejam de viés estadocêntrico e/ou etnocêntrico, no que diz respeito à relação estrutura-agência e às relações de poder.

Particularmente nesse trabalho de natureza teórica, interessa-me aprofundar a investigação sobre o uso do conceito de comunidades epistêmicas (HAAS, 1992; ANTONIADES, 2003) em chave discursiva pós-estrutural, tentando compreender como os agentes referidos por meio dessa significação atuam influenciando e produzindo políticas curriculares. Esse foco de investigação emerge em meus estudos tendo em vista que os atos de nomeação dos processos escolares como Natureza da Ciência emanam quase que exclusivamente de agentes públicos de notável destaque na produção de conhecimento acadêmico especializado, expressando como a equação conhecimento/poder é estruturante desse processo (HAAS, 1992; ANTONIADES, 2003; BALL, 2006; DIAS, 2016). Interessa-me, assim, investigar a atuação de tais agentes na nomeação e disseminação dessa política curricular, uma vez que, por meio de publicações em periódicos nacionais e internacionais, conferências, intercâmbios acadêmicos e atuações em esferas governamentais (HAAS, 1992; BALL, 1994; BALL, 1998; DIAS; LÓPEZ, 2006; DIAS, 2016), influenciam e produzem discursos sobre a qualidade da educação científica e, por extensão, sobre o que é um sujeito cientificamente educado, um bom professor de ciências, uma boa proposta curricular de ciências e, de modo mais amplo, uma sociedade racional. Para Ball (2006, p. 18-19), por exemplo, ao mesmo tempo em que seria ingênuo sugerir qualquer relação direta entre debates sociopolíticos e preocupações acadêmicas, seria perigoso achar que "as ciências humanas, como os estudos educacionais, permanecem fora ou acima da agenda política de gerenciamento da população ou, de algum modo, tem um status neutro incorporado em um racionalismo progressivo flutuante". Diz-nos, ainda, que nossas pesquisas e conceitos científicos não só podem como agem na governamentalidade social, o que nos coloca o duplo dever de investigar tais políticas e os jogos discursivos jogados pelos distintos agentes atuantes nas políticas (BALL, 2006).

A preocupação teórico-metodológica acerca do uso do referido conceito em chave pós-estrutural surgiu a partir da constatação teórica de que algumas conceituações críticas e pós-estruturais precisam ser atentamente cotejadas com outros registros discursivos pós-estruturais, tendo em vista possíveis (in)compatibilidades no que diz 
respeito ao alcance heurístico de cada recurso teórico específico (LOPES; CUNHA; COSTA, 2013; LOPES, 2016; MACEDO, 2016; DIAS, 2016). Assim, investigo como a problemática da subjetividade política e do pertencimento identitário são trabalhados no conceito de comunidades epistêmicas (HAAS, 1992; ANTONIADES, 2003), e como esse conceito pode (ou não) ser incorporado ao modo discursivo pós-estrutural (LACLAU; MOUFFE, 2015; BUTLER, 2015a) de pesquisar fenômenos políticos educacionais ${ }^{3}$. Algumas provocações me guiam nessa investigação: (I) quais as características fundantes e o que significa pertencer a uma comunidade epistêmica? (II) quem são seus integrantes e como se organizam/atuam politicamente? (III) quais são os mecanismos que permitem inferir determinada identidade política aos seus membros? (IV) como tal operador conceitual pode ser incorporado em um registro discursivo e pós-estrutural de investigação sobre subjetivação política? Para tentar responder tais questões, desenvolvo, na seção seguinte, argumentos sobre o modo como a subjetividade, a identidade e a atuação política são tratadas em chave discursiva pós-estrutural (LACLAU; MOUFFE, 2015; BUTLER, 2015a). Em seguida, abordo o conceito de comunidades epistêmicas (HAAS, 1992; ANTONIADES, 2003), destacando o modo como os autores configuram a subjetividade, a atuação política e o pertencimento comunitário nessa abordagem. $\mathrm{Na}$ quarta seção, levanto possíveis impasses teóricos que emergem nas superfícies de contato entre essas abordagens analíticas, tentando identificar os deslocamentos de foco necessários ao cotejamento dos dispositivos conceituais investigados. Por fim, argumento em torno da defesa de que, feitas algumas ressalvas heurísticas, pode ser plausível incorporar tal conceito em chave pós-estrutural, evitando assim a produção de constatações teóricas conflituosas entre si nas investigações sobre os modos de atuação dos agentes epistêmicos na produção de políticas curriculares.

\footnotetext{
${ }^{3}$ Destaco que não é intenção criticar a noção de comunidades epistêmicas pela falta de atenção aos princípios pós-estruturais. Mais do que uma diferenciação oposicional e anacrônica, investigo como tal conceito pode ser compatibilizado na chave pós-estrutural de pesquisa ou, ao menos, incorporado de modo crítico. Nesse cotejamento conflituoso de dispositivos teóricos, tento mostrar como a linguagem sobre identificação política se modifica, impondo certas restrições metodológicas, ao aderirmos ao pósestruturalismo. Não é intenção, portanto, produzir um relato evolutivo e linear culminando em prescrições sobre o melhor caminho investigativo, mas ponderar sobre como se deslocam agendas investigativas nesse cotejamento, analisando aquilo que os operadores conceituais viabilizam e bloqueiam nas análises.
} 


\section{Atuação política, discurso e performatividade em chave pós-estrutural}

Foi então o momento em que a linguagem invadiu o campo problemático universal; foi então o momento em que, na ausência de centro ou de origem, tudo se torna discurso - com a condição de nos entendermos sobre esta palavra -, isto é, sistema no qual o significado central, originário ou transcendental nunca está absolutamente presente fora de um sistema de diferenças. A ausência de significado transcendental ${ }^{4}$ amplia indefinidamente o campo e o jogo das significações. (DERRIDA, 2011, p. 409-410)

Inicio esta seção com Derrida (2011), pois seus escritos foram e têm sido influentes no forjar de uma ambiência propícia a uma profusão de narrativas teóricas pós-estruturais implicadas na desestabilização do real, da identidade, da linguagem e da política, reverberando tanto na teoria butleriana como na laclauniana. Tanto em Butler (2015a; 2015b) como em Laclau e Mouffe (2015) é possível encontrar relatos de como sujeitos e construtos aglutinadores do tipo nós - comunidades - se constituem identitária e politicamente a partir de um ponto de vista pós-estrutural. Inicialmente, considero ser concebível afirmar que os autores compartilham uma perspectiva discursiva do real, isto é, conferem ao discurso um estatuto ontológico incontornável. Isso significa dizer que todo pensamento acerca do social, da subjetividade e da política é constituído na e pela linguagem, em toda sua provisoriedade e precariedade, ou seja, a linguagem institui aquilo que ela nomeia, ultrapassando a função de mera reflexão neutra e especular do real. Nesse sentido, é comum entre os autores a rejeição à ideia de que a linguagem é mero instrumento externo de descrição do real, que é apenas o meio pelo qual se nomeiam objetos plenamente independentes e anteriores à linguagem. Essa abertura ontológica do sujeito, da identidade e do social na linguagem reverbera diretamente no modo como constroem seus relatos de subjetividade e atuação política.

\footnotetext{
${ }^{4}$ A noção de significado transcendental em Derrida (2001, p. 26) diz respeito àquilo que "em si mesmo, em sua essência, não remeteria a nenhum significante, excederia à cadeia dos signos e não mais funcionaria, ele próprio, em um certo momento, como significante". O conceito de significado transcendental é marcado pela ideia de um significante agindo fora do jogo da significação, um significante que, supostamente, teria alcançado um ponto externo garantidor de estabilidade no mar turbulento das significações, teria atingido um fundamento, um centro que o livraria da instabilidade da própria discursividade.
} 
Desde já, é preciso pontuar que o relato que Butler (2015a; 2015b) nos oferece acerca da subjetividade e da política da identidade é marcado por uma visão de agência cindida e fraca do sujeito que nada tem de autonomia soberana em sua capacidade de ação, mas que é fissurada por uma condição irredutível de alienação às normas ${ }^{5}$ que formou e pelas quais foi formado em suas redes de sociabilidade. Em sua concepção de agência, o sujeito é invadido, primeira e primariamente, por normas que o precedem e excedem, atuando, paradoxal e ambivalentemente, como limitantes e facilitadoras da capacidade de ação. "Trata-se de uma noção que está em oposição à de uma autonomia irrestrita e metafísica do sujeito plenamente centrado e consciente, marcada por uma agência autodeterminada e teleológica" (PIMENTEL-JÚNIOR; CARVALHO; SÁ, 2017) da identidade e da ação social. A essa desorientação ontológica do sujeito, que desde o início é despossuído de uma relação de transparência consigo mesmo, corresponde um princípio de infundamentação última que impede o alcance de construtos tidos como próprios e anteriores à própria eventualidade política de nomeação identitária. Com essa despossessão da agência e do sujeito em relação a si mesmo e aos outros, a autora se coloca contra o raciocínio fundacionista da política da identidade, o qual "tende a supor que primeiro é preciso haver uma identidade para que os interesses políticos possam ser elaborados, e, subsequentemente, empreender a ação política" (BUTLER 2015a, p. 245). Para ela, não há necessidade de existir "um agente por trás do ato, mas que o agente é diversamente construído no e através do ato" (BUTLER, 2015a, p. 245). Em sua teoria, o raciocínio fundacionista presume falsamente que (I) "só se pode estabelecer a ação mediante o recurso a um eu pré-discursivo, mesmo que esse eu se encontre no centro de uma convergência discursiva”; e (II) "que ser constituído pelo discurso significa ser determinado por ele, com a determinação excluindo a possibilidade de ação" (BUTLER, 2015a, p. 246). Essa criação despossuída e fissurada do sujeito, da identidade e da sua capacidade de ação (BUTLER, 2015a; BUTLER, 2015b) tem implicações no modo como a autora compreende a ação política de construtos sociológicos do tipo nós.

\footnotetext{
5 “A norma não produz o sujeito como seu efeito necessário, tampouco o sujeito é totalmente livre para desprezar a norma que inaugura sua reflexividade; o sujeito luta invariavelmente com condições de vida que não podia ter escolhido. Se nessa luta a capacidade de ação [...] funciona de alguma maneira, é dentro de um campo facilitador e limitante de restrições" (BUTLER, 2015b, p. 31). Portanto, a normatividade opera simultaneamente restringindo e viabilizando a criação de si em um quadro de inteligibilidade que nos excede e constitui, ou seja, ela não extingue, determina e/ou satura a agência do sujeito, mas opera constitutivamente impondo restrições.
} 
Para Butler, qualquer construto aglutinativo "é sempre e somente uma construção fantasística, que tem seus propósitos, mas que nega a indeterminação e a complexidade internas [...], e só se constitui por meio da exclusão de parte da clientela que simultaneamente busca representar" (BUTLER, 2015a, p. 245). Cabe destacar que, em sua teoria, a impossibilidade de representação total não é uma falta dada pela incapacidade panóptica de atender às múltiplas demandas identitárias provenientes de espaçostempos culturais distintos, mas uma incapacidade dada pela própria instabilidade da significação, pelo próprio processo dinâmico e falho de criação de um nós na linguagem ${ }^{6}$. Nesse sentido, a significação instituinte de qualquer fronteira - um construto identitário do tipo eu ou nós, por exemplo - é sempre marcada pelo seu fracasso constitutivo, gerando configurações aglutinativas sempre inconsistentes e habitadas por Outros que nos desorientam e desapossam de presença plena. As demarcações e operações de valor fronteiriço são, nesse sentido, sempre imprecisas e remetem muito mais a relações de poder do que a caracteres e atributos próprios e/ou pessoais. Em sua teoria, portanto, qualquer nós é uma formação sempre incerta, marcada pela multiplicidade de processos diferenciais que excedem e desafiam, interna e externamente, a própria demarcação da fronteira, contestando maneiras outras e subversivas de subjetivação.

Se a construção da identidade e da agência se dá mediante incontroláveis e indisciplinados processos de significação, e se a tentativa de demarcação de fronteiras estáveis é apenas uma operação fantasística que tenta negar a indeterminação e frear os processos diferenciais, é possível afirmar que em Butler (2004; 2015a; 2015b) a ação política se dá num quadro de performatividade. Com essa noção, a autora remete a construções dramáticas e contingentes de sentidos que emergem em meio a processos de subjetivação impossíveis de se prolongarem no tempo e no espaço, em virtude de sua nodosidade ontológica aos eventos por meio dos quais tomou forma. Isso significa que a identidade, a comunidade e a subjetivação política em Butler (2015a; 2015b) só pode ser compreendida mediante os próprios termos e condições dos atos por meio dos quais elas emergem e se colocam na atividade política. Termos e condições estes, por sua vez, sempre contextualmente formados, tendo em vista que os processos de significação

\footnotetext{
6 "Se a identidade se afirma por intermédio de um processo de significação, se é desde sempre significada e se, mesmo assim, continua a significar à medida que circula em vários discursos interligados, a questão da ação não deve ser respondida mediante um recurso a um eu que preexista à significação" (BUTLER, 2015a, p. 247).
} 
comportam repetições que são governadas pelos registros dos quadros de inteligibilidade e, ao mesmo tempo, tensões governadas pela lógica da diferença. Essa criação performática da atividade política impede não apenas o fechamento pleno, mas também uma perenidade absoluta de qualquer instância sociológica do tipo nós, remetendo a um eterno vir a ser da identidade aglutinativa que, por sua vez, resiste à (a/re)presentação plena, adiando indefinidamente o jogo da significação e da política.

Em sua teoria (BUTLER, 2004; 2015a; 2015b), a criação do gênero e da política de identidade como performatividade remete a uma atuação que não dispõe de uma causalidade atemporal, mas se encadeia discursivamente numa duração espaço-temporal ligando-a a uma imanência radical ${ }^{7}$. Isto é, a sua emergência é dada na atuação, nem antes tampouco fora dela sendo guiada por algum princípio teleológico externo capacitador de um ponto privilegiado de ação. Isso indica que a performatividade política, em sua teoria, remete a instâncias discursivas imanentes, isto é, sem centro referencial transcendental e independente capaz de determinar os rumos dessa atividade. Ao lado e relacionado a essa dimensão imanente da performatividade, está o duplo papel conferido por Butler (2015a) à temporalidade da repetição, isto é, da repetição estilizada que, ao mesmo tempo, permite ao sujeito reencenar e produzir novas experiências de significação $^{8}$. Coerente ao seu modo de conceber a agência, isso significa que sua compreensão da performatividade política em nada remete a uma consciência absoluta operando em causa própria e fundamental, mas a uma consciência cuja soberania é limitada, primeira e primariamente, pelos quadros coletivos de inteligibilidade que

\footnotetext{
7 Atribuir uma dimensão imanente à performatividade como operação política em Butler (2004; 2015a; 2015b) significa estar atento ao fato de que, em sua teoria, a performatividade, como aspecto fundamental da política, se dá imersa em um quadro de despossessão, isto é, opera na possibilidade de (re)organizações subversivas dos quadros de inteligibilidade e arranjos sociais e identitários os quais os sujeitos não escolheram e pelos quais foram formados, levando a uma agência contestatória local e não totalitária, ampliando capacidades contextuais de intervenção e participação. Não há, portanto, um sujeito emancipado, portador de uma linguagem própria e independente, capaz de agência universal, atuando numa política de coalizão com as normas, mas ações despossuídas de linguagens próprias vinculadas à crítica à naturalização dos quadros de inteligibilidade por meio da reiteração anômala dos próprios termos restritivos desse quadro.

8 “Essa repetição é a um só tempo reencenação e nova experiência de um conjunto de significados já estabelecidos socialmente; e também é a forma mundana e ritualizada de sua legitimação. Embora existam corpos individuais que encenam essas significações estilizando-se em formas do gênero, essa 'ação' é uma ação pública. Essas ações têm dimensões temporais e coletivas, e seu caráter público não deixa de ter consequências [...]" (BUTLER, 2015a, p. 242). Isso retira a noção de gênero/corpo/identidade de um modelo fundacionista, deslocando-o para outro que tem como primariamente constitutivo a temporalidade social.
} 
desapossam o sujeito de uma visão privilegiada do rumo das relações sócio-históricas e, ao mesmo tempo, não conseguem determiná-lo por completo.

Nesse sentido, essa dupla temporalidade que habita a performatividade remete tanto às tradições discursivas por meio das quais se formatam quadros de inteligibilidade mantenedores de relações de poder, como à possibilidade de subversão política aberta pelo movimento indefinido e incontrolável de significação desses discursos. Defendo que, em sua teoria, a força da performatividade política irrompe justamente nesse ponto de possibilidade de deslocamento e agência subversiva da/na linguagem, superfície ontológica simultaneamente limitante e facilitadora da capacidade de ação do sujeito. É por meio dessa repetição estilizada que a significação, baseada numa lógica operacional da diferença, cria possibilidades de escape e ação ao sujeito em um cenário de matrizes de inteligibilidade reguladoras, isto é, a política possível da subversão se dá em um ambiente discursivamente restritivo por meio do qual é possível a deformação desses arranjos naturalizados de subjetividade, identidade e ação, expondo seus limites na capacidade de conferir reconhecimento.

Inspirada na lógica da iterabilidade de Derrida ${ }^{9}$, Butler (2004) defende que o potencial subversivo de ruptura que habita a repetição não é um predicado acidental da significação, mas parte estrutural desse processo, o que comumente é negado tendo em vista as fortes sedimentações das formas de uso que constrangem a proliferação de sentidos não previstos. Isso permite inferir que é na (re)iteração, na qual se reafirma também, e constantemente, o poder normativo das formas reconhecíveis de inteligibilidade, que reside a potencialidade política da subversão. Não há, portanto, nessa noção, a manifestação de uma consciência absoluta que alcançaria a subversão por operar uma política de significação pautada na coalizão, antecipando a estrutura ideal da coalizão e, subsequentemente, fixando uma forma/conteúdo fundamental aos jogos performativos. A política performativa se dá mais por arbitrariedades imprevisíveis e incalculáveis da iteração significativa, por repetições parodísticas que denunciam efeitos

\footnotetext{
9 "A explicação de Derrida tende a acentuar a relativa autonomia da operação estrutural do signo, identificando a 'força' do performativo como um rasgo estrutural de todo signo, que deve romper com seu contexto anterior com o fim de manter sua iterabilidade como signo. A força do performativo, portanto, não é herdada de um uso anterior, mas se produz depois, precisamente na sua ruptura com o uso prévio. [...] Quando escreve que o performativo é 'repetitivo e citacional em sua estrutura', está se opondo claramente à explicação de Austin sobre a 'repetibilidade' como uma função da linguagem enquanto convenção social" (BUTLER, 2004, p. 240-241).
} 
fantasísticos de perenidade e naturalidade identitária (BUTLER, 2004; 2015a), do que por uma política de coalizão cujos termos do debate estão fixados e calculados de antemão. Essa fluidez, irregularidade e, em alguma medida, imprevisibilidade da ação política têm implicações heurísticas importantes para esse trabalho, como mostro a seguir.

Laclau e Mouffe (2015), por sua vez, ao focalizarem a ação política a partir de articulação de demandas, permitem interrogar a linguagem objetificante e determinista da política de subjetividade e pertencimento cultural expressa em construtos teóricos fundacionistas. Em sua teoria, o foco desloca-se da positividade equivalencial em relação àquilo que é tido como essencial à ação política, para os movimentos contingentes das respostas produzidas às necessidades sociais em rejeição a determinado elemento tido como ameaça comum (LACLAU; MOUFFE, 2015). Nessa chave interpretativa, é possível dizer que nada pode estabilizar definitivamente uma identidade, uma comunidade, uma sociedade, tampouco uma significação (MARHART, 2014; LACLAU; MOUFFE, 2015), isto é, nada pode vir plenamente à presença (DERRIDA, 2011).

O registro discursivo, evitando um relato determinista, essencialista e realista do social, focaliza as ações políticas e os processos de subjetivação no discurso, nas demandas e nos antagonismos, e não a posse de atributos pelos agentes aglutinados em uma prática articulatória. Compreender o processo de articulação nos termos dos antagonismos e demandas é importante para o entendimento de que é pelo discurso, e não antes dele, que as identificações sociais se constroem. Isto é, é por meio da prática articulatória que as subjetivações políticas emergem como construtos provisoriamente instituídos em relação a um corte antagônico comum, sem nenhum caráter positivo conferindo viscosidade inquestionável ao processo de aderência (MENDONÇA, 2014; BURITY, 2014). Outro aspecto importante a destacar é que, nesse registro, as atividades políticas são tentativas de preencher uma falta social constitutiva, conferindo à discursividade uma dinâmica sempre contingente, marcada pela impossibilidade última de suturar plenamente a significação (MARCHART, 2014; LACLAU; MOUFFE, 2015; LOPES, 2015).

Às necessidades sociais demandadas e tidas como capazes de preencher essa falta social, corresponde um princípio de contingência que opera restringindo a presença dessas mesmas necessidades, isto é, seu aspecto fundamental. Isso significa dizer que as 
necessidades são restringidas pela contingencialidade dos seus termos, impedindo a definição de um fundamento último capaz de suturar o social e, subsequentemente, a atividade política.

No relato laclauniano e mouffeano, a articulação política se dá a partir das equivalências entre demandas frente a um exterior representado como ameaça ao atendimento dessas mesmas demandas (MARCHART, 2014; LACLAU, MOUFFE, 2015). Isto é, os elementos apresentam uma irremediável diferença que, provisoriamente, são suavizadas tendo em vista a comum rejeição a um determinado inimigo (LACLAU, 2013). As diferenças irremediáveis entre os sujeitos são apenas estancadas em nome de uma articulação provisória, visando combater um determinado elemento tido como ameaça comum. Não há, portanto, nenhum atributo próprio aos agentes e/ou entre os agentes articulados, tendo em vista que os antagonismos são os elementos operadores da cadeia equivalencial (BURITY, 2014). É a partir dessa comum rejeição que a articulação discursiva se firma provisoriamente: sua constituição emerge em meio à aglutinações que nada tem de essencial ou positivo entre os elementos articulados, mas se dá pela eliminação de uma diferença comum à cadeia articulatória. É esse exterior constitutivo que forja a identificação, é ele que permite inferir a equivalência entre os elementos que, provisoriamente, engendram momentos nessa cadeia.

A articulação política expressa, portanto, uma tensão insuperável entre a lógica da equivalência e da diferença na ausência de um fundamento comum entre os equivalentes - estes mantêm as diferenças entre si -, apenas um exterior que forja a identificação provisória (MARCHART, 2014; LACLAU; MOUFFE, 2015). Nessa chave, portanto, a política e o discurso produzem a identificação, e não as identidades anteriormente formadas e conscientes, passíveis de aglomeração circunstancial.

Tanto a partir do relato butleriano (BUTLER, 2015a; 2015b) como do laclauniano e mouffeano (LACLAU; MOUFFE, 2015), é possível conceber a noção de sujeito, identidade, comunidade e atividade política como construtos inantecipáveis, abertos e inacabados, marcados pelos movimentos incessantes, complexos e contingentes de identificação/subjetivação política que se dão no acontecer da significação. Nessas teorias, a constituição discursiva das instâncias sociológicas (identidade, comunidade, etc.) envolvidas na política e o foco nas circunstâncias por meio das quais tais instâncias 
emergem, conferem alta fluidez aos processos políticos, abrindo-os às subjetivações imprevisíveis, às cisões, aos suplementos e aos excessos que acompanham e constituem todo e qualquer evento enunciativo (BHABHA, 2013; BUTLER, 2015a).

Simultaneamente, essa linguagem imprecisa e complexa da política permite bloquear e interromper o relato da capacidade de ação das instâncias de luta política fundado em uma linguagem objetivista e preexistente, anterior aos eventos políticos, mostrando que toda tarefa de demarcação de fronteiras plenamente rígidas é inglória e interessada em negar aquilo que, de outros, já se acha ali. O cotejamento da teoria butleriana com a laclauniana permite, portanto, inferir que a luta política não se dá entre estruturas sociais plenamente estáveis e conscientes daquilo que seus atributos lhes permite ser e do modo como lhes permite agir, formando uma coalizão fixa, mas, antes, ocorre entre estruturas descentradas e provisoriamente articuladas, incapazes de remeter a um centro referencial em torno e por meio do qual a luta política e os termos dos debates estariam definidos de uma vez por todas.

\section{A atuação política e a identidade das/nas comunidades epistêmicas}

Haas (1992) oferece uma abordagem que permite examinar "o papel que as redes de experts-baseados-em-conhecimento - comunidades epistêmicas - exercem na articulação de relações de causa e efeito de problemas complexos, ajudando os estados a identificarem seus interesses, definirem os termos dos debates coletivos, proporem políticas específicas, e identificarem pontos relevantes de negociação" (HAAS, 1992, p. 2). De acordo com ele, "o controle sobre o conhecimento e a informação é uma importante dimensão do poder, e a difusão de novas ideias e informações podem levar a novos padrões de comportamento, provando ser uma dimensão importante da coordenação de políticas nacionais e internacionais" (HAAS, 1992, p. 3). Assim, define uma comunidade epistêmica como uma "rede de profissionais com conhecimento e competência reconhecidos em um domínio particular, e com autoridade legitimada em conhecimentos politicamente relevantes dentro de um domínio ou área de conhecimento" (HAAS, 1992, p. 3). A atuação desses agentes nas esferas públicas e nas políticas nacionais e internacionais têm se intensificado diante da ausência de conhecimento, por parte dos legisladores, sobre problemas complexos e questões sociais específicas, demandando a 
presença de especialistas que os auxiliem nas tomadas de decisões, muitas vezes, alterando as próprias agendas políticas em direções imprevistas pelos legisladores bem como os termos dos debates propostos (HAAS, 1992; BALL, 2006; ANTONIADES, 2003).

Uma comunidade epistêmica pode ser formada a partir de profissionais provenientes de uma variedade de campos disciplinares e outros backgrounds sóciohistóricos e identitários (HAAS, 1992). Embora possam pertencer a diferentes campos disciplinares, Haas (1992) afirma que a comunidade epistêmica apresenta: (I) "um conjunto de crenças e princípios normativos compartilhados, os quais provêem os membros da comunidade com uma racionalidade baseada em valores para a ação social” (HAAS, 1992, p. 3); (II) “crenças causais compartilhadas, que derivam de sua análise de práticas que conduzem ou contribuem para um conjunto central de problemas no seu domínio, e que servem então como base para elucidar as múltiplas ligações entre possíveis ações políticas e resultados desejados" (HAAS, 1992, p. 3); (III) "noções compartilhadas de validação - isto é, critérios intersubjetivos internamente definidos de deliberação e validação de conhecimento no domínio de sua especialidade” (HAAS, 1992, p. 3); e, (IV) “um empreendimento político comum - ou seja, um conjunto de práticas comuns associadas a um conjunto de problemas para o qual sua competência profissional está dirigida, presumivelmente fora da convicção de que o bem-estar humano será reforçado como uma conseqüência" (HAAS, 1992, p. 3). Outras características das comunidades epistêmicas fazem referência ao compartilhamento de formas intersubjetivas de compreensão e saberes, de padrões de racionalidade, de projetos políticos delineados a partir de valores comuns, de práticas discursivas comuns, e de comprometimento na aplicação e produção de conhecimento (HAAS, 1992; ANTONIADES, 2003).

Haas (1992) diz que o termo comunidades epistêmicas tem sido definido e usado de várias formas, e muito frequentemente, para se referir às comunidades científicas. No que diz respeito às políticas educacionais e curriculares em particular, o uso desse conceito em diferentes trabalhos mostram algumas nuances sobre o nível, os canais e os mecanismos de influência e atuação das comunidades epistêmicas, entretanto, de modo amplo, tal significante comumente se refere aos discursos produzidos por agentes produtores de conhecimento especializado (DIAS; LÓPEZ, 2006; BALL, 2006; 
MAINARDES, 2009; LOPES; MACEDO, 2011; DIAS, 2016). Haas destaca, entretanto, que as comunidades epistêmicas não são necessariamente constituídas por cientistas naturais ou por profissionais que apliquem as mesmas metodologias que tais cientistas, mas precisam compartilhar formas específicas de crença na verdade, sobretudo, aquelas baseadas nos métodos específicos da ciência ${ }^{10}$. Assume que o modo como utiliza o conceito de comunidades epistêmicas se assemelha à noção fleckiana de coletivo de pensamento e à noção de kuhniana de paradigma ${ }^{11}$, as quais, por sua vez, remetem a instâncias sociológicas constituídas por cientistas especializados em valores, métodos, técnicas e modos particulares de investigação científica, formados por meio de longos períodos de treinamento específico. Os conceitos da teoria moderna da ciência por Haas (1992), incorporados em sua definição de comunidades epistêmicas concebem estruturas sociológicas fortemente consolidadas e governadas a partir daquilo que é tido como comum aos membros de uma comunidade de praticantes de ciência.

Haas (1992) destaca o papel pragmático das comunidades epistêmicas no que diz respeito aos interesses dos estados. De acordo com ele, na medida em que demandas por informações precisas e conhecimentos específicos, que exigem aplicação de

\footnotetext{
${ }^{10}$ Haas distingue seu conceito de abordagens mais amplas e inespecíficas como as de Holzner e Marx (1979), que usam o conceito de comunidades epistêmicas em referência a uma fé compartilhada no método científico como uma forma de produção de verdade. De acordo com Haas, essa definição ignora o fato de que essa fé pode unir pessoas com diversas interpretações e dados ambíguos, o que o faz optar por uma definição mais restritiva, na qual "o que une os membros de uma comunidade epistêmica é a sua crença compartilhada na veracidade e na aplicabilidade de formas particulares de conhecimento ou verdade específica" (HAAS, 1992, p. 4).

${ }^{11}$ Apesar de não ser intenção adentrar nas teorias modernas da ciência de Kuhn (2009) e Fleck (2010), destaco as definições dos conceitos citados por Haas na caracterização das comunidades epistêmicas. De um lado, o conceito de Fleck remete à ideia de que a gênese do conhecimento científico é um processo sócio-histórico e cultural, no qual a interação é a estrutura principal desse processo: "esse conceito se refere à condicionalidade social do pensamento, não deve ser entendido como um grupo fixo ou uma classe social. Um coletivo de pensamento existe sempre que duas ou mais pessoas intercambiam idéias" (FLECK, 2010, p. 149). Embora a noção fleckiana frise aspectos anti-classistas e anti-fixistas na produção dos coletivos de pensamento, remete à própria estrutura da cena interativa como base para o coletivo, isto é, recorre à positividade da estrutura de socialização para justificar a gênese do coletivo, mudando apenas o nível hierárquico dos limites discursivos da instância sociológica. Por outro lado, o conceito de Kuhn remete às "realizações científicas universalmente reconhecidas que, durante algum tempo, fornecem problemas e soluções modelares para uma comunidade de praticantes de uma ciência" (KUHN, 2009, p. 13). De acordo com Kuhn, o estudo dos paradigmas é o que prepara basicamente o estudante para ser membro de determinada comunidade científica, de modo que sua prática posterior raramente entrará em confronto com os fundamentos, métodos e regras comuns, compartilhados durante o treinamento, gerando um consenso aparente fundamental aos períodos de ciência normal. Em diferentes nuances, considero que a noção kuhniana, derivada em grande medida da noção fleckiana, apresenta ideias mais classistas e estruturalistas na consideração da comunidade científica. Ideia esta que reverbera mais fortemente na concepção desenvolvida por Haas.
} 
especialidades científicas, crescem nos meios sociais e legislativos, as comunidades epistêmicas emergem, proliferam e aparecem como importantes provedoras desses dados. Essa dimensão pragmática é fundamental à própria manutenção e status da comunidade epistêmica, pois, é com base na capacidade que esta tem de responder aos anseios e demandas governamentais que consegue manter-se como instância dinamizadora e interferente nas políticas nacionais e internacionais (HAAS, 1992; ANTONIADES, 2003).

Por meio desse movimento de solicitação de informações e delegações de atividades por parte dos legisladores, os membros de uma comunidade, segundo os autores, tornam-se fortes atores políticos, tanto a nível nacional como internacional, seja por meio de organismos mais independentes, seja por meio de atuações pontuais específicas. Destaco, no entanto, que, apesar dessa dimensão pragmática na formação e manutenção das comunidades a partir do provimento de informações estratégicas, a definição de Haas (1992) não abre a possibilidade de pensar a emergência da comunidade epistêmica no próprio movimento circunstancial decorrente das necessidades sociais identificadas em um dado contexto. Sua definição separa a comunidade, formada por traços próprios provenientes de suas práticas investigativas, das demandas sociais e governamentais mais amplas, conferindo certa plenitude ontológica à instância aglutinativa formada pelos cientistas.

Em outras palavras, existe uma dinâmica interna, anterior e independente de consolidação da comunidade e, ao mesmo tempo, uma dinâmica externa decorrente de atuações circunstanciais ligadas a necessidades sociais mais amplas. Ou seja, a abordagem das comunidades epistêmicas é simultaneamente marcada por aspectos internalistas e externalistas, vinculando a formação e identidade dessa instância social tanto aos movimentos investigativos dos cientistas quanto às demandas sociais. Isso não significa dizer que o conhecimento produzido pelas comunidades é alheio aos interesses sociais, apenas afirma que os valores e atributos de interesse que fundam a comunidade não estão totalmente subordinados a questões sociopolíticas, mas às dinâmicas internas do grupo.

Considero concebível pensar que o conceito de comunidade epistêmica (HAAS, 1992; ANTONIADES, 2003) segue na direção de uma política comunitária em que a ideia é 
alcançar o consenso, suplantando as diferenças, na busca de acordos que possam conferir uma identidade à própria comunidade, bem como positividade aos princípios compartilhados pelos seus membros. Em sua abordagem ao mesmo tempo internalista e externalista, a comunidade desenvolve e apresenta um background sócio-histórico de valores, métodos e práticas que servem de base às suas ações políticas quando solicitadas pela esfera pública. É possível ponderar que sua concepção busca mostrar que a comunidade existe para estabelecer uma determinada ordem, dada a existência de diferenças que povoam a comunidade, necessitando de valores, práticas e premissas comuns para fins de ação social.

Isso quer dizer que as diferenças não são negadas, não há homogeneidade simbólica entre os agentes do grupo. Ao mesmo tempo, trata-se de uma questão de disposição com a diferença, que é concebida como uma dificuldade que a comunidade deve suplantar, compartilhando fundamentos comuns para a ação política e representatividade. A pressuposição implícita e, de certa forma explícita, é que a comunidade deve compartilhar valores objetivos e externos aos membros, atingindo certo grau de consenso independente de particularidades, sendo tais atributos aquilo o que dá sustentação ao processo aglutinativo. À sistematização tecnológica dos atributos comunitários, corresponde uma linguagem realista e externa aos sujeitos epistêmicos que, uma vez dominada a partir de treinamento, permite-lhes conferir certa rubrica identitária. Ou seja, há um desejo de estancar as subjetivações e lutas políticas em formas objetivas, esmaecendo as dissonâncias dentro da comunidade, pelo menos em parte daquilo que ela pensa e pratica, sendo esse o fundamento a partir do qual se pode afirmar certa identidade ao grupo.

Isso se concretiza a partir da retirada da agenda política da comunidade, das questões controversas, a fim de criar um consenso racional em torno do qual a comunidade gira. Reitero que isso não significa negá-las, mas relegá-las ao espaço privado dos sujeitos epistêmicos que a compõem, pressupondo que as controvérsias são prejudiciais ao espaço público da comunidade. Tal política de subjetividade e pertencimento age, portanto, tentando estabelecer a base comum, bloqueando, simultaneamente, a expressão das particularidades dos sujeitos, e relegando-as a níveis mais privados. 
Em âmbito coletivo, a ação política da comunidade epistêmica (HAAS, 1992; ANTONIADES, 2003) se dá, estruturalmente, a partir de um jogo complexo de dinâmicas interdependentes, internas e externas à comunidade, cujo fundamento repousa na identificação plenamente objetiva de quem está fora ou dentro da comunidade exercendo influência sobre quem. Defendo que, de modo ambivalente, essa delimitação precisa acaba tanto por negligenciar aspectos de subordinação das dinâmicas subjetivas comunitárias aos interesses sociais, como por conferir maior poder de consciência e ação política aos membros da própria comunidade a partir dos seus backgrounds fixos e partilhados. Em outras palavras, no que diz respeito à dinâmica das ações políticas de subjetividade e pertencimento nesse registro, o que vale, de certa forma, para negligenciar aspectos influentes externos, vale para conferir mais poder às questões internas comunitárias. Entretanto, o status e o poder de influência da comunidade conferidos por instâncias públicas só são possíveis na medida em que essas últimas têm seus anseios resolvidos e sanados mediante o provimento de informações e ações especializadas.

A política de subjetividade e pertencimento expressa no conceito de comunidades epistêmicas (HAAS, 2992; ANTONIADES, 2003) busca, portanto, a unidade pautada na posse de atributos plenos, tratando a diferença como coisa (BHABHA, 2013). Embora não seja possível afirmar que o conceito remeta a uma monotonia cultural comunitária, a diferença e a política de pertencimento ficam atravancadas na positividade dos atributos - e podem ser vários -, tidos como próprios e essenciais aos membros. O foco, portanto, restringe-se à coisa que, uma vez possuída, permite inferir pertencimento e conferir potencial de ação, o que torna, em último exame, o processo de localização e análise de atuação dos agentes epistêmicos em políticas educacionais mais preciso e claro. Nesse registro, portanto, a prioridade recai sobre os agentes e seus atributos, deslocando os atos e as significações para segundo plano da política. Se o foco, nessa abordagem, fica restrito ao consenso e à posse de atributos representativos da comunidade de pertencimento epistêmico, em um registro pós-estrutural, como espero ter deixado claro, o foco reside no próprio movimento político incessante de articulação de demandas (LACLAU; MOUFFE, 2015). Como desenvolvo nas próximas seções, defendo que esse deslocamento permite manter certa conexão na diferença, isto é, articular sem expulsar a 
constante produção de diferenças que ocorre em meio a qualquer ato de valor demarcatório/fronteiriço do tipo nós.

\section{Tensionando e deslocando os focos: o conceito de comunidades epistêmicas em chave pós-estrutural}

Como dito anteriormente, se o foco, nessa estrutura conceitual, fica mais restrito aos atributos, em um registro pós-estrutural o foco volta-se ao movimento circunstancial e performático de articulação de demandas. Defendo que, em um registro discursivo, a problemática do uso do conceito de comunidades epistêmicas (HAAS, 1992; BALL, 1998; ANTONIADES, 2003) se instaura no momento em que os autores fornecem um relato descritivo da comunidade no qual a ideia é objetificar a própria linguagem de diferenciação cultural da comunidade, que fica circunscrita à posse desses atributos fixos e plenamente presentes, tentando delimitar claramente atores e contextos que interferem e atuam nas políticas. Em outras palavras, defendo que o problema de incompatibilidade heurística se instaura quando pertencer a uma comunidade epistêmica significa instrumentalizar alguém para enunciar tais atributos próprios, um modelo de certa forma pautado na transmissibilidade e na reprodutibilidade, com vistas à formação anterior à atuação política.

Essa linguagem de fundação a priori da identidade, da comunidade e da sua ação política gera um isolamento contextual e subjetivo que tende a inviabilizar as indeterminações e os hibridismos culturais (BHABHA, 2013), dando a pensar que as subjetividades são originárias e plenamente firmadas a partir de backgrounds colecionados em outros espaços-tempos de atuação política. Isso reverbera no potencial heurístico da abordagem, criando uma linguagem plenamente concreta e objetiva, dando a pensar que as significações produzidas em cada contexto são puras e atuam mecanicamente em coalizão umas com as outras a partir da circulação entre contextos.

Trata-se, também, de uma lógica representativa de pertencimento que reflete na antecipação da identidade em uma presença à espera do alcance via treinamento, isto é, o percurso de vinculação previamente calculado e posto como condição à identidade política, remetendo mais a uma política de coalizão cujos termos dos debates já estão dados. Uma lógica que, de certa forma, desconsidera a irremediável distância ontológica 
entre representante e representado, emanando uma ideia de subjetividade política e pertencimento pautado na materialidade discursiva (FOUCAULT, 2008) e tecnológica dos seus atributos, tentando torná-la plenamente repetível, presente, transparente e translúcida, incontaminável em qualquer contexto. Se o foco restringe-se à coisa dita e/ou possuída, torna-se obsoleta a diferença e privilegia-se a equivalência do grupo, isto é, nega-se, em certa medida, a indeterminação e a complexidade inerente a qualquer estrutura/instância aglutinativa (BUTLER, 2015a), de modo a transparecer que não há exclusão constitutiva nesse ato demarcatório. O campo de pertencimento é claro, transparente aos membros e translúcidos aos demais que desejam entrar e compartilhar daquilo que já preexiste independentemente.

No que diz respeito ao deslocamento parcial de foco dos valores, normas e práticas para a competência técnica decorrente de uma formação disciplinar, remetendo à identidade e à atuação dos agentes epistêmicos a campos disciplinares, trata-se de uma estratégia que tampouco permite desestabilizar o relato do pertencimento e da subjetividade política pela posse de caracteres essenciais. É possível afirmar, em acordo com Butler (2015a), que essas categorias identitárias disciplinares presumidas como fundantes da política comunitária trabalham simultaneamente limitando e restringindo, $a$ priori, as possibilidades de atuação da própria comunidade. Aquilo que vale pra identificar e legitimar a atuação, nessa linguagem, vale também para restringir e bloquear as próprias dinâmicas culturais da comunidade.

Ambivalentemente, portanto, as competências disciplinares capacitam para a ação e a subordinam, em alguma medida, à posse dos atributos fundamentais da rubrica disciplinar. Em chave pós-estrutural, diferentemente, a ideia de que há um conhecimento independente e a priori que, uma vez dominado, permite conferir aos sujeitos uma determinada identidade é questionável. Ao invés disso, considera-se que tais atos de nomeação são incapazes de fixar identidades ao mesmo tempo em que expressam articulações hegemônicas que permitem, provisória e contingencialmente, identificar sujeitos a tradições disciplinares, sem nenhuma positividade plena (LOPES; MACEDO, 2011). Isto é, o campo e/ou a disciplina não é uma presença, mas um nome cuja estabilidade, tradicionalmente formada em acordos sociais, alude à presença mesmo sem nenhuma positividade fundamental. 
Outro aspecto problemático no processo de compatibilização heurística da abordagem das comunidades epistêmicas em chave pós-estrutural diz respeito à dinâmica de atuação política da comunidade, que remete à ideia de que existem contextos plenamente independentes, isto é, um dentro e um fora previamente dados e claramente demarcados. Essa tentativa de estabelecer um dentro e um fora a priori que permite identificar a ação política específica é, em chave pós-estrutural, vista como uma operação interessada na estabilidade e na coerência das fronteiras, uma tecnologia discursiva de controle social das significações que em nada impede os hibridismos e os deslizes culturais da significação (BUTLER, 2015a). Essas definições de interno e externo são precisamente problemáticas em um registro discursivo na medida em que são construções interessadas em estabilizar os sujeitos e a coerência de suas ações, dando respaldo à formação de uma frente de coalizão e, subsequentemente, às restrições identitárias que ela impõe.

O estabelecimento de um dentro e um fora categóricos remete à ideia de que tanto as identidades das estruturas sociológicas mais amplas como as dos próprios sujeitos constituintes dessas estruturas são unificadas, internamente coerentes e persistentes no tempo, culminando normalmente em análises presas em uma distinção binária difícil de desestabilizar, precisamente pelo fato de que o apelo a essa sistematicidade tecnológica expulsa e/ou oculta as descontinuidades e, subsequentemente, a lógica da diferença que abala qualquer estrutura. Nos termos butlerianos (2015a), podemos dizer que, ao remeter a contextos como entidades presentes, a abordagem das comunidades epistêmicas situa os sujeitos e a comunidade em um espaço ontológico anterior ao campo cultural que articulam por meio do discurso.

Assim sendo, discurso e cultura deixam de ser constitutivos dos agentes e da comunidade e passam, no máximo, a exercer alguma influência sobre eles, enredam-nos (BUTLER, 2015a) sem penetrá-los e constituí-los, fundando as instâncias sociológicas dentro/fora - em uma linguagem impermeável, deixando-as intactas frente à própria cultura que esperam responder em ação social. Diferentemente, a problematização desse aspecto fronteiriço da atuação política remete à ideia de que, em chave pós-estrutural, a comunidade não apenas é constituída na cultura e no discurso, como também é constitutivamente habitada pela dissonância e pela diferença. Assim, o pensamento de 
que a comunidade e o seu fora são instâncias plenamente sólidas em termos identitários é substituído pelo de que todo ordenamento comunitário é tensionado pelos seus outros, e que ele só pode vir à presença mediante omissões, resistências e exclusões constitutivas do próprio ato de afirmação identitária (BHABHA, 2013; BUTLER, 2015a; LACLAU; MOUFFE, 2015), o que o torna um processo de identificação sempre parcial e provisório em seu acontecimento.

Com isso, é possível dizer que, em chave pós-estrutural, não apenas a possibilidade de superação da diferença e da dissonância que habita qualquer instância sociológica é questionável, mas também sua desejabilidade. Resistências e diferenças habitam e são constantemente geradas em qualquer circunscrição política comunitária. O desejo de tentar alcançar um consenso, um acordo sólido em torno de valores, práticas e atitudes comuns, fundados a partir de colecionismos de backgrounds que produzem um solo fundamental, é substituído por agendas radicalmente contextuais e pelo desejo de manutenção da pluralidade e da diferença, adiando continuamente a presentificação da identidade comunitária. Nessa abordagem, é nessa resistência à realização (BUTLER, 2015a; 2015b) que reside o potencial subversivo da política e da cultura, isto é, criando a possibilidade de mudança para além da mesmidade política e cultural.

Assim, em chave pós-estrutural, é possível afirmar que não há primeiro uma identidade comum para depois se formar uma comunidade. A comunidade se forma na própria subjetivação política, no modo como responde a determinados problemas, em ato. Isso significa dizer que é na ação política que reside o momento aglutinador, a fusão política, não no acordo, no solo comum, tampouco em uma identidade comunitária preexistente que vem a se manifestar em casos particulares. Trata-se de uma ação política performática (BUTLER, 2015a) que não se prolonga no tempo e no espaço a partir da coleção de atributos fundamentais, mas desfaz-se no próprio encerramento do ato político. A atividade política da comunidade passa a comportar, em chave pós-estrutural, um elemento maior de imprevisibilidade, estando aberta às subjetivações imprevisíveis, expandindo-a para além da subordinação simbólica que a política pautada na lógica da identidade impõe ao grupo. A identidade comunitária não se prolonga no espaço-tempo, aliás, ela é apenas uma construção discursiva momentânea interessada em viabilizar certos modos de compreensão daquilo a que se refere, e bloquear outras leituras 
possíveis. A identificação comunitária, portanto, em chave pós-estrutural, emerge no instante em que performatiza a política, desaparecendo no momento em que a atividade política cessa e os antagonismos se enfraquecem, ou seja, ela não sobrevive à performance política que a gerou.

\section{Considerações finais}

Meu objetivo neste ensaio é não resolver o conflito que lhe é constitutivo, mas dar a pensar e, nesse movimento, apresentar algumas ponderações sobre (in)compatibilidades teórico-metodológicas e potenciais heurísticos no modo eclético como venho operando pesquisas sobre políticas curriculares. Em chave pós-estrutural, por um lado, venho tentando compreender a ideia de que a superação da pluralidade e o alcance de um solo comum podem não ser imperativos à ação política (LACLAU; MOUFFE, 2015; BUTLER, 2015a; LOPES; MACEDO, 2011; DIAS, 2016); por outro lado, essa superação parece ser condição no conceito de comunidades epistêmicas (HAAS, 1992; BALL, 1998; ANTONAIDES, 2003). Trata-se, portanto, de desvincular a diferença como ameaça à ação social e à identidade.

Defendo que uma das maiores tensões com a incorporação desse conceito em chave pós-estrutural diz respeito ao atravancamento da diferença em posse de atributos, a diferença como coleção de coisas, o que reverbera na criação de relatos objetivistas da linguagem e realistas da subjetividade, da identidade e do pertencimento comunitário. Pensada dessa forma, as comunidades estariam todas convivendo em autenticidade própria, imunes aos hibridismos e à produção de diferença intra-coletivo de pensamento. Defendo que, ao ser cotejado em chave pós-estrutural, essa abordagem apresenta algumas incompatibilidades teóricas (background sócio-histórico, competência disciplinar, identidade como posse, auto-suficiência contextual, universalismos normativos, sistematização objetivista de atributos, etc.) que poderiam limitar o alcance heurístico, a meu ver mais amplo, dos trabalhos implicados em perspectiva discursiva.

Outro ponto polêmico diz respeito ao pertencimento como destino. A ideia de que pertencer à comunidade significa caminhar um percurso já dado de antemão, antecipado via projeção normativa de métodos e práticas tidos como próprios, é questionável em um 
registro pós-estrutural. Essa gana realista de fixidez e positividade restringe o pertencimento à enculturação, dando pouco espaço para que as normas sejam questionadas e/ou diferidas, subordinando os sujeitos a fortes constrangimentos de iniciação sem possibilidades de escape.

A crítica à abordagem das comunidades epistêmicas não significa a celebração da desagregação. Isso significaria, a meu ver, a crítica a uma essência única em defesa da pluralidade de essências. A intervenção pós-estrutural problematiza aquilo que pode estar no interior mesmo das comunidades de pertencimento, realçando e abrindo espaço à diferença, bem como questionando a formação de identidades anteriores à política. Isso significa chamar atenção para o fato de que toda identidade é circundada por atos de exclusão, que toda circunscrição é imprecisa e tensionada por aquilo que ela precisa excluir para constituir-se, expressando mais as relações de conhecimento/poder do que uma naturalidade inquestionável; assim, convém aceitar que todo nós é uma operação sociológica que só se constitui mediante a exclusão de parte daqueles que tenta representar, tornando-a uma construção que resiste à presença final (BUTLER, 2015a; 2015b).

Defendo que a incorporação do conceito de comunidades epistêmicas em chave pós-estrutural pode significar a assunção de que certa distinção sociológica pode ser produtiva na identificação parcial dos agentes/discursos atuantes na política, levando em consideração os distintos jogos de linguagem nos processos de diferenciação cultural. Não significa, portanto, presumir que essa distinção signifique o alcance de um consenso pleno entre os membros articulados de uma comunidade, como se dentro desse cerco demarcatório os membros houvessem atingido um acordo fundamental em torno de atributos plenamente presentes. Significa apenas aceitar que é parte dos processos de diferenciação cultural produzir novas linguagens, novos relatos, formas contextuais de produzir valores e signos tidos como "próprios", por mais que esse próprio seja somente uma ilusão criada pela própria estabilidade adquirida por certo modo de falar. Aceitar o valor heurístico de certa distinção sociológica não significa, portanto, negar a indeterminação e a complexidade constitutiva de qualquer instância aglutinativa do tipo nós e de suas fronteiras, apenas aceitar certo grau de diferenciação entre jogos de linguagem na disputa pela nomeação dos fenômenos educacionais. 
Em meus estudos, tenho explorado os desafios desse cotejamento indisciplinado de dispositivos teóricos, prezando pela compreensão daquilo cada um deles viabiliza e, ao mesmo tempo, restringe nas análises em torno dos fenômenos políticos que envolvem nomeação da identidade dos processos escolares como Natureza da Ciência. Partindo das constatações produzidas nesse trabalho, tenho tentado operar com algumas características da abordagem das comunidades epistêmicas sem desprezar as (in)compatibilidades que tal registro apresenta em chave pós-estrutural. Isso tem me levado a ponderar sobre algumas questões que levanto sem a pretensão de esgotá-las e/ou resolvê-las, nesse momento final.

Talvez, uma forma importante de incorporar esse conceito nas pesquisas sobre políticas curriculares seja ( $\mathrm{I}$ ) deslocar o foco dos atributos e das fronteiras para o modo como um determinado grupo responde às demandas educacionais em determinado espaço-tempo de atuação política. Isso significaria dizer que não há comunidade epistêmica plena e anterior às respostas que oferecem, mas apenas modos como essas comunidades respondem ao que está posto em um determinado espaço-tempo de subjetivação política. Ao mesmo tempo em que inviabiliza uma atribuição fixista de atributos, esse deslocamento de foco das fronteiras para as respostas confere maior fluidez à investigação do modo como sujeitos se aglutinam frente ao que nomeiam como inimigo comum, permitindo pensar com mais dinamicidade desde as estratégias discursivas, os termos e o modo como mobilizam o debate na construção e identificação dessa ameaça, até o modo como prescrevem possíveis resoluções para os impasses gerados por esse inimigo. Isso poderia trazer, ao mesmo tempo, (II) certa noção de distinção e identidade, e inviabilizar a atribuição à comunidade de formas positivas de estar no mundo, delimitadas por fronteiras rígidas. Isso significaria, em última análise, abrir a noção de comunidades epistêmicas às subjetivações políticas inantecipáveis. Não se trata de apenas abalar a unidade identitária - seja ela individual, comunitária, etc. -, mas uma intervenção no sentido de abarcar a constitutividade do diferir em qualquer operação demarcatória que preze pela unidade.

A meu ver, outro aspecto importante a pontuar é que a incorporação desse conceito em chave pós-estrutural requer também (III) um deslocamento de foco dos agentes para os discursos produzidos pelos mesmos, borrando parcialmente a 
identificação dos agentes atuantes nas políticas. Em chave pós-estrutural, tal mecanismo de compatibilização se faz importante tendo em vista o modo cindido e fraco como a agência e a identidade do sujeito são construídas, interrompendo a narrativa do sujeito plenamente consciente de si e de suas tomadas de decisão tendo em vista os quadros normativos que precedem e excedem o mesmo.

Assim, nos estudos que venho desenvolvendo, interessa-me mais investigar quais são os impactos dos discursos produzidos em torno do significante Natureza da Ciência do que os agentes veiculadores de tais discursos, uma vez que os discursos permitem focalizar as atividades políticas de significação e não a identidade e/ou os instrumentos de ação dos agentes, como se estes fossem perenes e estivessem sempre prontos. Tem me interessado desenvolver e defender a ideia de que, em chave pós-estrutural, mesmo mantendo certos traços sociológicos característicos da abordagem das comunidades epistêmicas, parece-me mais produtivo focalizar tanto o modo como demandas são produzidas e significações são hegemonizadas em resposta às questões educacionais, quanto os impactos que os discursos, e não seus portadores, têm na produção dessas mesmas demandas e nas políticas educacionais curriculares.

Deslocar o foco da positividade da identidade dos sujeitos e dos seus atributos para as (IV) práticas de significação permite desestabilizar a ideia de que tanto a identidade como os atributos são superfícies dadas no espaço-tempo, isto é, entidades ontologicamente fixadas pela linguagem que se disponibilizam para a ação a partir de solicitações circunstanciais. Localizar a política na prática de significação permite não apenas romper com os fundamentos que estabilizam a política em dinâmicas contextuais estanques supostamente dotadas de presença plena, mas também colocar como políticos os próprios termos pelos quais essas fundações são articuladas. Defendo, assim, que esses deslocamentos de foco em chave pós-estrutural permitem pensar nos processos culturais e políticos que giram em torno das disputas pela nomeação de qualquer identidade e, por extensão, da identidade de processos escolares das Ciências, de maneira mais dinâmica e imprevisível, aberta ao inevitável porvir da significação. 


\section{Referências}

ANTONIADES, Andreas. Epistemic communities, epistemes and the construction of (world) politics. Global Society, v. 17, n. 1, p. 21-38, 2003.

BALL, Stephen. Educational reform: a critical and post-structural approach. Buckingham: Open University Press, 1994.

BALL, Stephen. Cidadania Global, consumo e política educacional. In: SILVA, L. H. (Org.) A escola cidadã no contexto da globalização. Petrópolis: Vozes, 1998, p. 127-137.

BALL, Stephen. Sociologia das Políticas Educacionais e Pesquisa Crítico-Social: uma revisão pessoal das políticas educacionais e da pesquisa em política educacional.

Currículo sem Fronteiras, v. 6, n. 2, p. 10-32, jul./dez., 2006.

BALL, Stephen; MAGUIRE, Meg; BRAUN, Annette. Como as escolas fazem as políticas: atuação em escolas secundárias. Ponta Grossa: Editora UEPG, 2016.

BHABHA, Homi. O local da cultura. Belo Horizonte: Ed. UFMG, 2013.

BURITY, Joanildo Albuquerque. Discurso, política e sujeito na teoria da hegemonia de Ernesto Laclau. In: MENDONÇA, D. de.; RODRIGUES, L. P. (Orgs.). Pós-estruturalismo e Teoria do Discurso: em torno de Ernesto Laclau. $2^{\mathrm{a}}$ ed. Porto Alegre: EDIPUCRS, 2014.

BUTLER, Judith. Lenguaje, poder e identidad. Madrid: Síntesis, 2004.

BUTLER, Judith. Problemas de gênero: feminismo e subversão da identidade. Rio de Janeiro: Civilização Brasileira, 2015a.

BUTLER, Judith. Relatar a si mesmo: crítica da violência ética. Belo Horizonte: Autêntica, 2015b.

DERRIDA, Jacques. Posições. Tradução Tomaz Tadeu da Silva. Belo Horizonte: Autêntica, 2001.

DERRIDA, Jacques. A escritura e a diferença. São Paulo: Perspectiva, 2011.

DIAS, Rosanne Evangelista; LÓPEZ, Silvia Braña. Conhecimento, interesse e poder na produção de políticas curriculares. Currículo sem Fronteiras, v. 6, n. 2, p. 53-66, jul./dez., 2006.

DIAS, Rosanne Evangelista. Políticas de currículo e avaliação para a docência no espaço Iberoamericano. Práxis Educativa, v. 11, n. 3, p. 590-604, set./dez., 2016.

FLECK, Ludwik. Gênese e desenvolvimento de um fato científico. Trad. George Otte e Mariana Camilo de Oliveira. Belo Horizonte: Fabrefactum, 2010.

FOUCAULT, Michel. A Arqueologia do saber. Rio de Janeiro: Forense Universitária, 2008. 
HAAS, Peter. Introduction: epistemic communities and internacional policy coordination. International Organization, v. 46, n. 1, p. 1-35, 1992.

HOLZNER, Burkhart; MARX, John. Knowledge application: the knowledge system in society. Boston: Allyn and Bacon, 1979.

KUHN, Thomas. A estrutura das revoluções científicas. São Paulo: Perspectiva, 2009.

LACLAU, Ernesto; MOUFFE, Chantal. Hegemonia e estratégia socialista: por uma política democrática radical. São Paulo: Intermeios, 2015.

LOPES, Alice Casimiro. Democracia nas políticas de currículo. Cadernos de Pesquisa, v. 42, n. 147, p. 700-715, set./dez., 2012.

LOPES, Alice Casimiro; CUNHA, Érika Virgílio Rodrigues da; COSTA, Hugo Heleno Camilo. Da recontextualização à tradução: investigando políticas de currículo. Currículo sem Fronteiras, v. 13, n. 3, p. 392-410, set./dez., 2013.

LOPES, Alice Casimiro. Por um Currículo sem Fundamentos. Linhas Críticas, v. 21, n. 45, p. 445-466, maio/ago., 2015.

LOPES, Alice Casimiro. A teoria da atuação de Sthephen Ball: e se a noção de discurso fosse outra? Archivos Analíticos de Políticas Educativas, v. 24, n. 25, 2016.

LOPES, Alice Casimiro; MACEDO, Elizabeth. Teorias de currículo. São Paulo: Cortez, 2011.

MACEDO, Elizabeth. Currículo como espaço-tempo de fronteira cultural. Revista

Brasileira de Educação, v.11, n. 32, p. 285-372, maio/ago., 2006.

MACEDO, Elizabeth. Cultura performativa e pesquisa em educação: desafios para a ação política. Cadernos de Pesquisa, v. 45, n. 158, p. 752-774, dez., 2015.

MACEDO, Elizabeth. Por uma leitura topológica das políticas curriculares. Archivos Analíticos de Políticas Educativas, v. 24, n. 26, 2016.

MAINARDES, Jefferson. Análises de políticas educacionais: breves considerações teóricometodológicas. Contrapontos, v. 9, n. 1, p. 4-16, jan./abr., 2009.

MARCHART, Oliver. Apresentação: teoria do discurso, pós-estruturalismo e paradigma da Escola de Essex. In: MENDONÇA, D. de.; RODRIGUES, L. P. (Orgs.). Pós-estruturalismo e

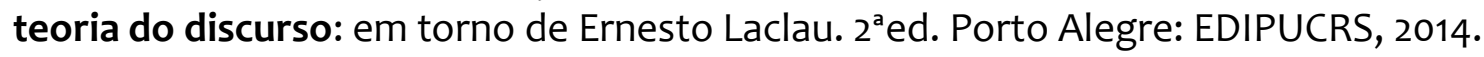

MENDONÇA, Daniel de. A impossibilidade da emancipação: notas a partir da teoria do discurso. In: MENDONÇA, D. de.; RODRIGUES, L. P. (Orgs.). Pós-estruturalismo e teoria do discurso: em torno de Ernesto Laclau. $2^{\mathrm{a}}$ ed. Porto Alegre: EDIPUCRS, 2014.

PIMENTEL-JÚNIOR, Clívio; CARVALHO, Maria Inez da Silva de Souza; SÁ, Maria Roseli Gomes Brito de. Pesquisa (auto)biográfica em chave pós-estrutural: conversas com Judith Butler. Práxis Educativa, v. 12, n. 1, p. 203-222, jan./abr., 2017. 
Recebido em: 21/02/2017 Aprovado em: 05/06/2017

Universidade do Estado de Santa Catarina - UDESC Programa de Pós-Graduação em Educação - PPGE Revista Linhas Volume 19 - Número 41 - Ano 2018 revistalinhas@gmail.com 